\title{
The role of lifestyle, health, and work in educational inequalities in sick leave and productivity loss at work
}

\author{
Suzan J. W. Robroek • Frank J. van Lenthe • \\ Alex Burdorf
}

Received: 30 August 2011/Accepted: 18 June 2012/Published online: 7 July 2012

(C) The Author(s) 2012. This article is published with open access at Springerlink.com

\begin{abstract}
Purpose To investigate the influence of lifestyle, health, and work conditions in the association between education and productivity loss at work and sick leave.

Methods Employees of six companies filled out a questionnaire on demographics, lifestyle-related, health, and work-related factors, and productivity loss at work and sick leave at baseline $(n=915)$ and after 1-year $(n=647)$.

Results Employees with a low education were more likely to report productivity loss at work $(\mathrm{OR}=1.49$, $95 \%$ CI 0.98-2.26) and sick leave (OR $=1.81,95 \% \mathrm{CI}$ 1.15-2.85). After adjustment for lifestyle, health, and work conditions, the association between education and productivity loss at work did not attenuate. Work conditions attenuated the association between low education and sick leave $(\mathrm{OR}=1.62,95 \% \mathrm{CI}$ 1.01-2.61), and additional adjustment for health and lifestyle-related factors further reduced the strength of the association $(\mathrm{OR}=1.42,95 \%$ CI 0.86-2.34).

Conclusion Work conditions and lifestyle-related factors partly explained the association between education and sick leave, but did not influence the association between education and productivity loss at work. The educational differences in sick leave prompt for interventions that address behavioral aspects as well as work-related and lifestyle-related factors.
\end{abstract}

Keywords Productivity loss at work - Sick leave . Education · Inequalities

S. J. W. Robroek · F. J. van Lenthe · A. Burdorf ( $\square)$ Department of Public Health, Erasmus MC, University Medical Center Rotterdam, PO Box 2040, 3000 CA Rotterdam, The Netherlands e-mail: a.burdorf@erasmusmc.nl

\begin{abstract}
Abbreviations
PA Physical activity

BMI Body mass index
\end{abstract}

\section{Introduction}

Workers with a low education or working in lower occupational social classes have a higher risk of disability retirement and sick leave (Beemsterboer et al. 2009; Duijts et al. 2007; Leinonen et al. 2011). The mechanisms through which socioeconomic position affects these outcomes are not yet established. Working conditions as well as lifestylerelated factors and health might play a role in the causal pathway of educational inequalities in productivity loss at work and sick leave. Insight into such underlying factors is of importance to design successful interventions to decrease educational inequalities in sick leave.

A low educational level is associated with both strenuous physical and psychosocial working conditions (Schrijvers et al. 1998), which are determinants of both productivity loss at work and sick leave (Alavinia et al. 2009a; Martimo et al. 2009; Moreau et al. 2004). Strenuous working conditions might therefore contribute to educational inequalities in productivity loss at work and sick leave. The role of working conditions on the relation between educational inequalities and sick leave has been studied before. Previous studies found that a substantial part of the relation between lower occupational class and sick leave could be attributed to physical working conditions and a low job control (Laaksonen et al. 2010a; Melchior et al. 2005; Niedhammer et al. 2008). Melchior et al. (2005) reported that a set of working conditions, with both physical and psychosocial work-related factors (e.g., demands, control, 
social support), accounted for $16 \%$ (men) to $25 \%$ (women) of the occupational class differences in sick leave. Laaksonen et al. (2010a) found that the occupational group differences in sickness absence reduced by about $40 \%$ after adjustment for physical working conditions.

The role of other factors on the relation between educational level and sick leave is less clear. An unhealthy lifestyle and poor health are also more prevalent among individuals with a low education than among better educated individuals (Kamphuis et al. 2008; Kunst et al. 2005; Mackenbach et al. 2008) and have also been found to be associated with productivity loss at work and sick leave (Bernaards et al. 2007; Gates et al. 2008; Laaksonen et al. 2009; Neovius et al. 2009; Pronk et al. 2004; Robroek et al. 2011; Schultz and Edington 2007; Van Duijvenbode et al. 2009). Laaksonen et al. (2009) reported that smoking and overweight explained part of the relation between occupational class and sick leave. However, the role of lifestylerelated factors in potential educational differences in productivity loss at work remains largely unknown.

In summary, little is known on the mechanisms through which socioeconomic factors affect sick leave, and productivity loss at work. In the current study, both lifestyle-related and work-related factors can be analyzed simultaneously to investigate their relative influence on the association between educational level and productivity loss at work and sick leave. It is aimed to get insight into the role of health, lifestyle-related and work-related factors in educational inequalities in productivity loss at work and sick leave.

\section{Methods}

Study design, participants, and recruitment

Participants were employees from healthcare organizations $(n=2)$, commercial services $(n=2)$, and the executive branch of government $(n=2)$, with the main occupational groups: clerical workers, financial workers, managers, nurses and nursing aides, and policemen. The study took place in The Netherlands between October 2007 and November 2010. Within the participating companies, the study was announced through e-mail, internet, and/or a company magazine. Three companies restricted the maximum number of participants on a 'first in' principle. Participants enrolled voluntarily in the study by visiting the study website and completing the baseline questionnaire on lifestyle-related factors, health, work demands, productivity loss at work, and sick leave. Subsequently, they could participate in a physical health check. One year after the baseline measurements, participants were asked to fill out the first follow-up questionnaire. Thirty-six workers were excluded due to working $<12 \mathrm{~h}$ per week for the company, and an additional 36 did not complete the full questionnaire. Of the 915 participants with baseline information on educational level, lifestyle-related factors, productivity loss at work, and sick leave, $71 \%$ filled out the 1-year follow-up questionnaire ( $n=647$ ). The Medical Ethics Committee of Erasmus MC, University Medical Center in Rotterdam, The Netherlands, approved the study and all participants gave written informed consent.

\section{Outcomes}

\section{Productivity loss at work}

At baseline and 1-year follow-up, productivity loss at work was measured with the quantity scale of the Quantity and Quality (QQ) method (Brouwer et al. 1999). This measure showed a moderate correlation with objective work output $(r=0.48)$ among floor layers (Meerding et al. 2005). Respondents were asked to indicate how much work they actually performed during regular hours on their most recent regular workday, compared with normal. The amount of productivity was measured on a scale from 0 (nothing) to 10 (regular amount). The outcome productivity loss at work was classified into three categories: no productivity loss $($ score $=10), 10-20 \%$ productivity loss (score $=8$ or score $=9)$, and $30 \%$ or more productivity loss at work (score of 7 or lower).

\section{Sick leave}

Sick leave was derived from the work ability index (WAI) and measured both at baseline and 1-year follow-up (Tuomi et al. 1998). Participants were asked to indicate on a 5-point ordinal scale how many days in the past 12 months they were not able to work due to health problems. The outcome sick leave was classified into three categories: no sick leave, 1-9 days, and 10 days or more with sick leave.

\section{Determinants}

\section{Individual characteristics}

In the baseline questionnaire, participants were asked about their age, sex, education, and ethnicity. Educational level was assessed by the highest level of education completed and was defined as low (primary school, lower and intermediate secondary schooling, or lower vocational training), intermediate (higher secondary schooling or intermediate vocational schooling), and high (higher vocational schooling or university). Two categories were created for ethnicity: Dutch and other, according to the standardized procedures described by Statistics Netherlands (2004). 


\section{Lifestyle-related factors}

Self-reported lifestyle-related factors were measured both at baseline and at 1-year follow-up. Physical activity (PA) was measured in the baseline questionnaire by the short version of the international physical activity questionnaire (IPAQ), which assessed vigorous and moderate intensity PA (Craig et al. 2003). The average time spent on PA per day was calculated. Walking was not included in this calculation, since casual walking is regarded a light-intensity activity. For all behaviors, a dichotomous variable was calculated for non-compliance with the national recommendations. For insufficient moderate PA, a cut-off point of $<30$ min of PA per day was used, and for insufficient vigorous PA, a cut-off point of $<3$ times a week vigorous PA. For insufficient fruit and vegetable intake, the cut-off point was $<400 \mathrm{~g}$ of fruit and vegetables. Fruit and vegetable intake was measured with the nine-item validated Dutch Food Frequency Questionnaire (Bogers et al. 2004). Smoking was defined as current smoking status, and excessive alcohol use as drinking 15 or more glasses of alcohol per week for women and 22 or more glasses for men.

\section{Health indicators}

Self-reported health and body mass index (BMI) were measured at baseline and at 1-year follow-up. The first question of the short form-12 (SF-12) questionnaire was used to measure perceived general health and dichotomized into 'poor or moderate' and 'good to excellent' (Ware et al. 1996). In the physical health check, height and weight were measured to calculate the body mass index (BMI) and to categorize individuals as normal weight (BMI $<25 \mathrm{~kg} / \mathrm{m}^{2}$ ), overweight $\left(25 \leq \mathrm{BMI}<30 \mathrm{~kg} / \mathrm{m}^{2}\right)$, and obese (BMI $\geq$ $30 \mathrm{~kg} / \mathrm{m}^{2}$ ). In the first follow-up, weight was self-reported in the questionnaire.

\section{Work-related factors}

The self-reported work-related factors were measured in the baseline questionnaire.

Participants were asked to indicate whether their current job is mainly physically or mentally demanding. In addition, specific psychosocial and physical work demands were asked. The following psychosocial factors were measured with an abbreviated version of a validated Dutch questionnaire about psychosocial job demands on job stress: work demands (6 items, Cronbach's $\alpha=0.82$ ), job control (4 items, Cronbach's $\alpha=0.89$ ), skill discretion (4 items, Cronbach's $\alpha=0.78$ ), and support from colleagues (6 items, Cronbach's $\alpha=0.74$ ) and supervisor (6 items,
Cronbach's $\alpha=0.79$ ) (Van Veldhoven and Meijman 1994). Questions on work demands were related to excessive work, and insufficient time to complete the work. Job control concerned influence on the planning of tasks, and influence on the pace of work. Skill discretion related to creativity, varied work, and required skills and abilities. Support from colleagues and supervisors was measured with questions related to conflicts, understanding, possibility to ask for help and to count on them, and the atmosphere. For all questions, a four-point scale was used with ratings 'never', 'sometimes', 'often', and 'always'. A standardized sum score was calculated for each dimension separately, and workers with a score in the upper quartile were regarded as exposed to the psychosocial risk factor.

Physical load in the current job concerned the regular presence of working in awkward postures, and lifting heavy loads. For both factors, a four-point scale was used with rating 'seldom or never', 'now and then', 'quite a lot', and 'a lot' during a normal workday. The answers 'quite a lot' and 'a lot' were classified as high exposure (Elders and Burdorf 2001).

\section{Statistical analyses}

Descriptive statistics were used for characteristics of the study population.

In order to study the association of the dependent variables (' $10-20 \%$ productivity loss at work' ' $30 \%$ or more productivity loss at work', ' $1-9$ days sick leave', and' 10 or more days sick leave') with educational level, lifestylerelated factors, health, and work-related factors general estimating equations (GEE) were used. GEE is suitable for the analysis of repeated measurements within participants, analyzing the associations between the variables of the model at different time-points simultaneously (Twisk 2003). The absence of productivity loss at work and sick leave were reference categories. In all models, demographic and work-related factors were considered to be time independent, and all associations were adjusted for sex, age, and ethnicity. The associations were adjusted for ethnicity because of its association with educational level, health, and labor force status (Schuring et al. 2009). The odds ratios (OR) were estimated as measure of association with corresponding $95 \%$ confidence intervals (95\% CI).

In order to study the influence of lifestyle-related factors, perceived general health, and work-related factors on the associations between educational levels and productivity loss at work and sick leave, these factors were added separately to the basic statistical model describing the association between educational level and productivity loss at work or sick leave, adjusted for demographic confounders. All variables with an association with educational level 
$(p<0.20)$ and a statistically significant association with productivity loss at work or sick leave $(p<0.05)$ were selected to study the influence on the association between educational level and productivity loss at work and sick leave. A less stringent significance level was used to identify variables associated with educational level, to avoid that important variables would not end up in the final model. All analyses were carried out with SAS 9.2 statistical software package.

\section{Results}

Table 1 shows that at baseline, $33 \%$ of the subjects reported productivity loss at work during the previous workday and $59 \%$ lost at least one workday because of sick leave in the past 12 months. At 1-year follow-up, $30 \%$ of the participants reported productivity loss at work, and $52 \%$ reported sick leave. Productivity loss at work and sick leave were not associated (Cohen's $\kappa=0.07$ ).

Table 1 Baseline characteristics of participating employees in 6 companies $(n=915)$

\begin{tabular}{|c|c|c|c|c|c|c|c|c|}
\hline & \multicolumn{2}{|c|}{$\begin{array}{l}\text { Total } \\
(n=915)\end{array}$} & \multicolumn{2}{|c|}{$\begin{array}{l}\text { Low education } \\
(n=201)\end{array}$} & \multicolumn{2}{|c|}{$\begin{array}{l}\text { Intermediate education } \\
(n=303)\end{array}$} & \multicolumn{2}{|c|}{$\begin{array}{l}\text { High education } \\
(n=411)\end{array}$} \\
\hline & $n$ & $\%$ & $n$ & $\%$ & $n$ & $\%$ & $n$ & $\%$ \\
\hline \multicolumn{9}{|l|}{ Demographic factors } \\
\hline Female gender & 469 & 51 & 92 & 46 & 166 & 55 & 211 & 51 \\
\hline \multicolumn{9}{|l|}{ Age (years)* } \\
\hline$<39$ & 376 & 41 & 49 & 24 & 128 & 42 & 199 & 48 \\
\hline $40-49$ & 274 & 30 & 66 & 33 & 106 & 35 & 102 & 25 \\
\hline $50+$ & 265 & 29 & 86 & 43 & 69 & 23 & 110 & 27 \\
\hline Non-Dutch ethnicity & 147 & 16 & 49 & 24 & 43 & 14 & 55 & 13 \\
\hline \multicolumn{9}{|l|}{ Lifestyle-related factors } \\
\hline$<30 \mathrm{~min} /$ day moderate PA & 295 & 32 & 80 & 40 & 85 & 28 & 130 & 32 \\
\hline$<3 \mathrm{x} /$ wk 20 min vigorous $\mathrm{PA}$ & 646 & 71 & 144 & 72 & 203 & 67 & 299 & 73 \\
\hline$<400 \mathrm{~g}$ fruit and vegetable intake & 429 & 47 & 98 & 49 & 152 & 50 & 179 & 44 \\
\hline Current smoker & 164 & 18 & 47 & 24 & 49 & 16 & 68 & 17 \\
\hline Excessive alcohol user & 24 & 3 & 3 & 2 & 7 & 2 & 14 & 3 \\
\hline Overweight* & 274 & 34 & 66 & 39 & 95 & 35 & 113 & 31 \\
\hline Obese & 70 & 8 & 23 & 14 & 25 & 9 & 22 & 6 \\
\hline \multicolumn{9}{|l|}{ Health indicator } \\
\hline Poor or moderate general health* & 58 & 6 & 21 & 10 & 18 & 6 & 19 & 5 \\
\hline \multicolumn{9}{|l|}{ Work-related factors } \\
\hline Physically demanding job* & 145 & 16 & 51 & 25 & 47 & 16 & 47 & 11 \\
\hline Lifting heavy loads & 84 & 9 & 21 & 11 & 28 & 9 & 35 & 9 \\
\hline Awkward postures & 117 & 13 & 28 & 14 & 44 & 15 & 45 & 11 \\
\hline High work demands* & 291 & 32 & 56 & 28 & 89 & 29 & 146 & 36 \\
\hline Low job control* & 303 & 33 & 75 & 37 & 116 & 38 & 112 & 27 \\
\hline Low skill discretion & 242 & 26 & 49 & 24 & 98 & 32 & 95 & 23 \\
\hline Poor relation with colleagues & 263 & 29 & 47 & 23 & 99 & 33 & 117 & 29 \\
\hline Poor relation with supervisor & 255 & 28 & 49 & 24 & 82 & 27 & 124 & 30 \\
\hline \multicolumn{9}{|l|}{ Outcome } \\
\hline Productivity loss at work* & 302 & 33 & 81 & 40 & 99 & 33 & 122 & 30 \\
\hline $10-20 \%$ productivity loss at work & 179 & 20 & 49 & 24 & 57 & 19 & 73 & 18 \\
\hline$\geq 30 \%$ productivity loss at work & 123 & 13 & 32 & 16 & 42 & 14 & 49 & 12 \\
\hline Sick leave & 535 & 59 & 116 & 58 & 192 & 63 & 227 & 55 \\
\hline $1-9$ days sick leave & 404 & 44 & 78 & 39 & 139 & 46 & 187 & 46 \\
\hline$\geq 10$ days sick leave* & 131 & 14 & 38 & 19 & 53 & 17 & 40 & 10 \\
\hline
\end{tabular}

$P A$ physical activity

$* p<0.05$ (trend test) 
Productivity loss at work and 10 or more days sick leave were more prevalent among low educated employees as compared to better educated participants. Overweight and obesity and reduced perceived general health were also more prevalent among employees with a low education. Employees with a low educational level more often had physically demanding jobs and jobs with low job control than better educated participants.

Lifestyle-related, health, and work-related factors were not found to be correlated or were weakly correlated $(r<0.30)$, except the correlations between supervisor and colleague support $(r=0.37, p<0.001)$, between the several physical work demands, and between physical work demands and physical activity $(r=0.39, p<0.001)$.

Twenty-nine percent of the baseline participants were lost to follow-up. Individuals with insufficient fruit and vegetable intake $(\mathrm{OR}=0.65,95 \% \mathrm{CI} \quad 0.49-0.88)$ and smokers $(\mathrm{OR}=0.53,95 \%$ CI $0.37-0.75)$ were less likely to fill out the follow-up questionnaire than workers with a healthy lifestyle. Older employees $(\mathrm{OR}=3.01,95 \% \mathrm{CI}$ 1.86-4.86) were more likely to repeat participation at 1-year follow-up.

Productivity loss at work

As shown in Table 2, participants with a low educational level $(\mathrm{OR}=1.49,95 \%$ CI $0.98-2.26)$ and participants with insufficient vigorous $\mathrm{PA}(\mathrm{OR}=1.58,95 \% \mathrm{CI}$ 1.10-2.26) were more likely to report productivity loss at work. The strongest association was found between a poor health and productivity loss at work $(\mathrm{OR}=3.24,95 \% \mathrm{CI}$ 1.94-5.41). Low job control $(\mathrm{OR}=1.62,95 \%$ CI

Table 2 Univariate odds ratios (OR) and $95 \%$ confidence intervals (95\% CI) of individual characteristics, lifestyle-related and health factors, and work-related factors in relation with productivity loss at work and sick leave among employees in 6 companies $(n=647)$

\begin{tabular}{|c|c|c|c|c|c|c|c|c|c|}
\hline & \multirow{3}{*}{$\begin{array}{l}\mathrm{Pe} \\
\%\end{array}$} & \multicolumn{4}{|c|}{ Productivity loss at work } & \multicolumn{4}{|c|}{ Sick leave } \\
\hline & & \multicolumn{2}{|c|}{$10-20 \%^{\dagger}(n=130)$} & \multicolumn{2}{|c|}{$30 \%$ or $\operatorname{more}^{\dagger}(n=93)$} & \multicolumn{2}{|c|}{$1-9$ days $^{\ddagger}(n=305)$} & \multicolumn{2}{|c|}{10 or more days ${ }^{*}(n=97)$} \\
\hline & & OR & $95 \% \mathrm{CI}$ & OR & $95 \% \mathrm{CI}$ & OR & $95 \% \mathrm{CI}$ & OR & $95 \% \mathrm{CI}$ \\
\hline \multicolumn{10}{|l|}{ Educational level } \\
\hline Low & 21 & $1.46^{*}$ & $1.01-2.11$ & 1.49 & $0.98-2.26$ & 1.06 & $0.76-1.48$ & $1.81 *$ & $1.15-2.85$ \\
\hline Intermediate & 35 & 1.22 & $0.89-1.67$ & 1.28 & $0.87-1.87$ & 1.29 & $0.98-1.70$ & $1.85^{*}$ & $1.21-2.82$ \\
\hline High & 45 & 1.00 & - & 1.00 & - & 1.00 & - & 1.00 & - \\
\hline \multicolumn{10}{|l|}{ Lifestyle-related factors } \\
\hline$<30 \mathrm{~min} /$ day moderate $\mathrm{PA}$ & 30 & 1.19 & $0.90-1.57$ & 1.18 & $0.83-1.67$ & 0.86 & $0.68-1.09$ & 0.92 & $0.65-1.29$ \\
\hline$<3 \mathrm{x} /$ wk 20 min vigorous $\mathrm{PA}$ & 70 & 1.08 & $0.81-1.43$ & $1.58 *$ & $1.10-2.26$ & 1.20 & $0.95-1.52$ & 1.25 & $0.87-1.81$ \\
\hline$<400 \mathrm{~g}$ fruit and vegetable intake & 44 & 0.85 & $0.65-1.12$ & 1.00 & $0.73-1.38$ & 0.95 & $0.75-1.19$ & 1.12 & $0.81-1.56$ \\
\hline Current smoker & 15 & 1.16 & $0.81-1.67$ & 0.95 & $0.62-1.47$ & 1.35 & $0.97-1.87$ & 1.43 & $0.93-2.19$ \\
\hline Excessive alcohol & 3 & 0.65 & $0.28-1.53$ & 1.01 & $0.39-2.66$ & 1.05 & $0.49-2.22$ & 1.51 & $0.64-3.60$ \\
\hline Overweight & 35 & 1.18 & $0.87-1.62$ & 1.18 & $0.83-1.68$ & 1.02 & $0.79-1.34$ & $1.52 *$ & $1.01-2.30$ \\
\hline Obese & 9 & 1.12 & $0.68-1.83$ & 0.79 & $0.40-1.53$ & 0.76 & $0.48-1.22$ & $2.29 *$ & $1.27-4.12$ \\
\hline \multicolumn{10}{|l|}{ Health } \\
\hline Poor/moderate general health & 6 & $1.91 *$ & $1.10-3.32$ & $3.24 *$ & $1.94-5.41$ & $1.87 *$ & $1.11-3.16$ & $6.26^{*}$ & $3.47-11.29$ \\
\hline \multicolumn{10}{|l|}{ Work-related factors } \\
\hline Physically demanding job & 15 & 1.22 & $0.84-1.77$ & 1.13 & $0.72-1.77$ & 1.08 & $0.77-1.53$ & 1.47 & $0.93-2.32$ \\
\hline Lifting heavy loads & 9 & 1.15 & $0.73-1.81$ & 0.69 & $0.34-1.38$ & 1.13 & $0.72-1.76$ & 0.84 & $0.42-1.68$ \\
\hline Awkward postures & 13 & 0.98 & $0.65-1.81$ & 1.24 & $0.83-2.26$ & $1.62 *$ & $1.09-2.39$ & $2.21 *$ & $1.32-3.68$ \\
\hline High work demands & 31 & 1.17 & $0.87-1.57$ & 1.11 & $0.77-1.60$ & 1.23 & $0.94-1.61$ & 1.26 & $0.85-1.87$ \\
\hline Low job control & 32 & 1.10 & $0.82-1.47$ & $1.62 *$ & $1.16-2.28$ & $1.51 *$ & $1.16-1.96$ & $1.97 *$ & $1.36-2.86$ \\
\hline Low skill discretion & 27 & 1.30 & $0.96-1.78$ & 1.33 & $0.93-1.89$ & $1.52 *$ & $1.15-2.02$ & $1.93 *$ & $1.30-2.88$ \\
\hline Poor relation with colleagues & 28 & $1.40 *$ & $1.04-1.89$ & $1.61 *$ & $1.14-2.26$ & 1.16 & $0.89-1.53$ & $1.70^{*}$ & $1.17-2.47$ \\
\hline Poor relation with supervisor & 28 & $1.71 *$ & $1.27-2.31$ & $2.16^{*}$ & $1.53-3.05$ & 1.28 & $0.98-1.68$ & $1.78^{*}$ & $1.22-2.60$ \\
\hline
\end{tabular}

$P e$ prevalence in study population

$\dagger$ Reference category: no productivity loss

* Reference category: no sick leave

$* p<0.05$, adjusted for sex, age, and ethnicity 
1.16-2.28) and a poor relation with supervisors $(\mathrm{OR}=$ $2.16,95 \%$ CI 1.53-3.05) or colleagues (OR $=1.61,95 \%$ CI 1.14-2.26) were also associated with productivity loss at work. A statistically significant interaction was found between insufficient vigorous PA and educational level. After stratifying for educational level, insufficient vigorous PA was only associated with $30 \%$ or more productivity loss at work among better educated employees (OR = $3.76,95 \%$ CI 1.71-8.26). The combination of work-related factors did not explain the association between educational level and productivity loss at work (Table 3). The strength of the association between a low educational level and $30 \%$ or more productivity loss at work was not reduced after adjustment for health, work-related or lifestyle-related factors.

\section{Sick leave}

As shown in Table 2, individuals with a low $(\mathrm{OR}=1.81$, $95 \%$ CI 1.15-2.85) or intermediate educational level $(\mathrm{OR}=1.85,95 \% \mathrm{CI} 1.21-2.82)$ were more likely to have 10 or more workdays sick leave. Obesity was statistically significantly associated with more sick leave days after adjustment for gender, age, and ethnicity ( $O R=2.29$, $95 \%$ CI 1.27-4.12). The strongest association was found between perceived general health and sick leave $(\mathrm{OR}=6.26,95 \%$ CI 3.47-11.29). Several work-related factors were also associated with sick leave: working in awkward postures, low job control, low skill discretion, and a poor relation with colleagues or supervisor (Table 2). The combination of work-related factors partly explained the association between educational level and sick leave (Table 4). After adjustment for work-related factors, the strength of the association between a low educational level and 10 or more days of sick leave decreased from $\mathrm{OR}=1.81$ to $\mathrm{OR}=1.62 \quad(23 \%$ change $)$. Combined adjustment for work-related factors and perceived general health further reduced the strength of the association between a low educational level and 10 or more days of sick leave with an additional $4 \%$. After additional adjustment for overweight/obesity, the strength of the association between a low educational level and 10 or more days of sick leave further reduced with another $21 \%$ (48\% change from $\mathrm{OR}=1.81$ to $\mathrm{OR}=1.42$ ).

\section{Discussion}

In the current study, it was aimed to identify whether working conditions as well as lifestyle-related factors and health play a role in the causal pathway of educational inequalities in productivity loss at work and sick leave. Educational differences were found for productivity loss at work and sick leave. These educational differences in productivity loss at work and sick leave were particularly apparent in the more severe categories of productivity loss at work and sick leave. Unhealthy lifestyle-related factors, a poor general health, and unfavorable work conditions were also more prevalent among lower educated employees, but did not influence the association between education and productivity loss at work. Work-related factors and obesity did have an influence on educational differences in sick leave.

Previous research found educational differences in sick leave (Beemsterboer et al. 2009; Duijts et al. 2007). In our study, these findings were corroborated, especially for 10

Table 3 Effects of adjustment for work-related factors, health, and lifestyle-related factors on the association between educational level and productivity loss at work $(n=647)$

\begin{tabular}{|c|c|c|c|c|c|c|c|c|}
\hline & \multicolumn{4}{|c|}{$10-20 \%$ productivity $\operatorname{loss}^{\dagger}$} & \multicolumn{4}{|c|}{$30 \%$ or more productivity $\operatorname{loss}^{\dagger}$} \\
\hline & \multicolumn{2}{|c|}{ Low education } & \multicolumn{2}{|c|}{$\begin{array}{l}\text { Intermediate } \\
\text { education }\end{array}$} & \multicolumn{2}{|c|}{ Low education } & \multicolumn{2}{|c|}{$\begin{array}{l}\text { Intermediate } \\
\text { education }\end{array}$} \\
\hline & OR & $95 \% \mathrm{CI}$ & OR & $95 \% \mathrm{CI}$ & OR & $95 \% \mathrm{CI}$ & OR & $95 \% \mathrm{CI}$ \\
\hline Model 1: sex, age, and ethnicity & $1.46^{*}$ & $1.01-2.11$ & 1.22 & $0.89-1.67$ & 1.49 & $0.98-2.26$ & 1.28 & $0.87-1.87$ \\
\hline Model 2: model $1+$ reduced perceived general health & $1.45^{*}$ & $1.00-2.08$ & 1.21 & $0.88-1.65$ & 1.43 & $0.94-2.19$ & 1.28 & $0.87-1.87$ \\
\hline Model 3: model $1+$ work-related factors ${ }^{\mathrm{a}}$ & $1.54^{*}$ & $1.06-2.23$ & 1.24 & $0.90-1.70$ & $1.54 *$ & $1.01-2.35$ & 1.26 & $0.86-1.85$ \\
\hline Model 4: model $1+$ lifestyle-related factors ${ }^{\mathrm{b}}$ & $1.46^{*}$ & $1.02-2.11$ & 1.22 & $0.89-1.68$ & 1.50 & $0.98-2.30$ & 1.35 & $0.92-1.97$ \\
\hline Model 5: model $1+$ health + work-related factors & $1.53 *$ & $1.05-2.21$ & 1.23 & $0.90-1.70$ & 1.49 & $0.97-2.28$ & 1.27 & $0.86-1.86$ \\
\hline $\begin{array}{l}\text { Model 6: model } 1+\text { health }+ \text { work-related factors }+ \\
\text { lifestyle-related factors }\end{array}$ & $1.53 *$ & $1.06-2.22$ & 1.24 & $0.90-1.71$ & $1.54 *$ & $1.01-2.37$ & 1.32 & $0.90-1.94$ \\
\hline \multicolumn{9}{|l|}{${ }^{\dagger}$ Reference category: no productivity loss } \\
\hline \multicolumn{9}{|l|}{ * Reference category: high educational level } \\
\hline \multicolumn{9}{|c|}{${ }^{a}$ Work-related factors: low job control, poor relation with colleagues, and poor relation with supervisor } \\
\hline \multicolumn{9}{|c|}{ b Lifestyle-related factors: insufficient vigorous physical activity } \\
\hline$* p<0.05$ & & & & & & & & \\
\hline
\end{tabular}


Table 4 Effects of adjustment for work-related factors, health, and lifestyle-related factors on the association between educational level and sick leave

\begin{tabular}{|c|c|c|c|c|c|c|c|c|}
\hline & \multicolumn{4}{|c|}{$1-9$ days sick leave ${ }^{\dagger}$} & \multicolumn{4}{|c|}{10 or more days sick leave ${ }^{\dagger}$} \\
\hline & \multicolumn{2}{|c|}{ Low education ${ }^{*}$} & \multicolumn{2}{|c|}{$\begin{array}{l}\text { Intermediate } \\
\text { education }\end{array}$} & \multicolumn{2}{|c|}{ Low education* } & \multicolumn{2}{|c|}{$\begin{array}{l}\text { Intermediate } \\
\text { education }\end{array}$} \\
\hline & OR & $95 \% \mathrm{CI}$ & OR & $95 \% \mathrm{CI}$ & OR & $95 \% \mathrm{CI}$ & OR & $95 \% \mathrm{CI}$ \\
\hline Model 1: sex, age, and ethnicity & 1.06 & $0.76-1.48$ & 1.29 & $0.98-1.70$ & $1.81 *$ & $1.15-2.85$ & $1.85^{*}$ & $1.21-2.82$ \\
\hline Model 2: model $1+$ reduced perceived general health & 1.07 & $0.77-1.50$ & 1.30 & $0.99-1.72$ & $1.77 *$ & $1.12-2.81$ & $1.81 *$ & $1.18-2.79$ \\
\hline Model 3: model $1+$ work-related factors ${ }^{\mathrm{a}}$ & 1.00 & $0.71-1.41$ & 1.20 & $0.91-1.58$ & $1.62 *$ & $1.01-2.61$ & $1.69 *$ & $1.09-2.62$ \\
\hline Model 4: model $1+$ lifestyle-related factors ${ }^{\mathrm{b}}$ & 1.04 & $0.74-1.47$ & 1.29 & $0.97-1.71$ & $1.69 *$ & $1.05-2.75$ & $1.77 *$ & $1.14-2.77$ \\
\hline Model 5: model $1+$ work-related factors + health & 1.04 & $0.74-1.47$ & 1.22 & $0.92-1.62$ & 1.59 & $0.99-2.55$ & $1.65 *$ & $1.05-2.59$ \\
\hline $\begin{array}{l}\text { Model 6: model } 1+\text { work-related factors }+ \text { health }+ \\
\text { lifestyle-related factors }\end{array}$ & 0.98 & $0.69-1.40$ & 1.18 & $0.88-1.58$ & 1.42 & $0.86-2.34$ & 1.58 & $0.98-2.54$ \\
\hline
\end{tabular}

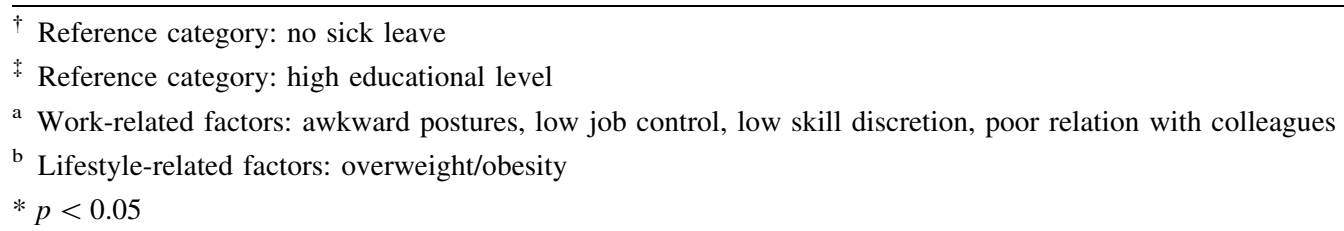

or more days with sick leave. We also found educational differences in productivity loss at work. Employees with a low educational level had a higher risk of productivity loss at work. Although productivity loss at work and sick leave were not associated, educational level was associated with both outcomes.

The results of this study imply that both work-related and lifestyle-related factors do play a role in the mechanisms through which socioeconomic position affects sick leave. Unhealthy lifestyle behaviors and a decreased perceived general health were more prevalent among lower educated persons (see also Kamphuis et al. 2008; Kunst et al. 2005; Mackenbach et al. 2008). For productivity loss at work, these factors did not change the associations between educational levels and productivity loss at work. However, the association between sick leave and educational level decreased after adjustment for work-related and lifestylerelated factors. The relation between a poorer general health, on one hand, and productivity loss at work or sick leave, on the other hand, was consistent over the educational groups. Adjusting for health status between educational groups did not lead to a reduction in the strength of the association between educational level and productivity loss at work or sick leave. This implies that the higher prevalence of health problems among lower educated workers is not a major factor in the pathway between educational level and sick leave. In accordance with the study of Laaksonen et al. (2010a), work-related factors and overweight/obesity had the biggest influence on the relation between educational level and sick leave. However, in the study of Laaksonen et al. (2010a), strenuous physical work conditions instead of psychosocial work conditions provided the strongest explanation for socioeconomic differences in sickness absence. In contrast with other studies (Alavinia et al. 2009b; Laaksonen et al. 2010b; Lund et al. 2006), we did not find an association between having a physically demanding job and sick leave, nor between lifting heavy loads and sick leave. A possible explanation might be that the proportion of workers with exposure to mechanical load was low in our study population. Although $9 \%$ was exposed to lifting heavy loads in our study, only $3 \%$ answered 'a lot' on the question how often they have to lift heavy loads. This might indicate that those workers who were classified as having strenuous work conditions in our study are not that highly exposed to the specific physical work conditions. The evidence from literature indicates that both psychosocial and physical work-related factors may play a role in explaining educational differences in sick leave (Laaksonen et al. 2010a; Melchior et al. 2005; Niedhammer et al. 2008). Therefore, interventions aimed at improving work conditions, especially at postures, job control, and skill discretion, among lower educated employees might reduce educational differences in sick leave. However, a large proportion of the educational differences in sick leave could not be explained by these factors. Other factors, like coping strategy, social support, and motivation to work, were not measured in our study and may be relevant in explaining educational differences in sick leave, but also in productivity loss at work (Rael et al. 1995; Smith et al. 2008). In addition, factors like organizational problems, machine breakdown, or personal issues might particularly influence productivity loss at work. This might also be an explanation for the lack of influence of an unhealthy lifestyle and unfavorable working conditions on 
the association between education and productivity loss at work.

Relations between lifestyle-related factors and sick leave are well studied. In previous research, a relation between obesity and sick leave was found, especially with long-term sick leave (Alavinia et al. 2009b; Neovius et al. 2009; Robroek et al. 2011; Van Duijvenbode et al. 2009). Concerning productivity loss at work less evidence is available on the specific role of lifestyle-related factors. We observed an association between insufficient vigorous physical activity and more than $30 \%$ productivity loss at work. However, this association was found only among better educated employees. A possible explanation might be found in the role of physical activity to reduce perceived stress. Vigorous physical activity may be a method to release stress in mentally demanding jobs and thereby decrease productivity loss at work (Hansen et al. 2010). It might be an interesting topic for future research to study whether physical activity buffers the relation between job demands and productivity loss at work in different types of work.

\section{Limitations}

Firstly, participation levels differed between companies, partly because three companies had restricted the maximum participation. However, baseline participation levels (ranging from 36 to $61 \%$ ) in the other companies without restrictions were comparable with other studies on health promotion programs at the worksite, and in a systematic review, no evidence was found for selective participation concerning health or lifestyle indicators (Robroek et al. 2009). Secondly, subjective single measures of productivity loss at work and sick leave were used. There is ongoing discussion on how to measure productivity loss at work in a reliable and valid way (Koopmanschap et al. 2005; Zhang et al. 2011). Objective measures of productivity loss at work are rarely available, and the quantity question of the QQ method was associated with objective work output among floor layers ( $r=0.48)$. A disadvantage of this method is that productivity loss is assessed during the previous regular workday and does not take into account the expected fluctuations in productivity loss within workers across workdays. Thirdly, as we described in the results, there is selective loss to follow-up. However, no selective loss to follow-up was found in the outcome measures. Fourthly, sickness absence has a multifactorial nature. Although we adjusted for several factors in the analyses, there may be confounders that were not taken into account. Last, self-reported health was measured with a single item. In a recent study, the reliability of the often used single question for general self-reported health was discussed. It was suggested that dichotomization may be a useful strategy for increasing the reliability of the measure in the total population (Zajacova and Dowd 2011).

\section{Conclusion}

In conclusion, educational differences were observed in productivity loss at work and sick leave. These differences could hardly be assigned to health. Work-related and lifestyle-related factors did attenuate the association between low education and sick leave, but did not influence the association between educational level and productivity loss at work. These educational differences in sick leave prompt for interventions that address behavioral aspects as well as work-related and lifestyle-related factors.

Acknowledgments This work was supported by ZonMw, The Netherlands Organization for Health Research and Development (grant number 62300039). Trial registration: Current Controlled Trials ISRCTN52854353.

Conflict of interest The authors declare that they have no competing interests.

Open Access This article is distributed under the terms of the Creative Commons Attribution License which permits any use, distribution, and reproduction in any medium, provided the original author(s) and the source are credited.

\section{References}

Alavinia SM, Molenaar D, Burdorf A (2009a) Productivity loss in the workforce: associations with health, work demands, and individual characteristics. Am J Ind Med 52:49-56. doi:10.1002/ ajim. 20648

Alavinia SM, Van den Berg TI, Van Duivenbooden C, Elders LA, Burdorf A (2009b) Impact of work-related factors, lifestyle, and work ability on sickness absence among Dutch construction workers. Scand J Work Environ Health 35:325-333

Beemsterboer W, Stewart R, Groothoff J, Nijhuis F (2009) A literature review on sick leave determinants (1984-2004). Int J Occup Med Environ Health 22:169-179. doi:10.2478/v10001009-0013-8

Bernaards CM, Proper KI, Hildebrandt VH (2007) Physical activity, cardiorespiratory fitness, and body mass index in relationship to work productivity and sickness absence in computer workers with pre existing neck and upper limb symptoms. J Occup Environ Med 49:633-640. doi:10.1097/JOM.0b013e318058202c

Bogers RP, Van Assema P, Kester AD, Westerterp KR, Dagnelie PC (2004) Reproducibility, validity, and responsiveness to change of a short questionnaire for measuring fruit and vegetable intake. Am J Epidemiol 159:900-909. doi:10.1093/aje/kwh123

Brouwer WB, Koopmanschap MA, Rutten FF (1999) Productivity losses without absence: measurement validation and empirical evidence. Health Policy 48:13-27. doi:10.1016/S0168-8510(99) 00028-7

Craig CL, Marshall AL, Sjöström M, Bauman AE, Booth ML, Ainsworth BE et al (2003) International physical activity questionnaire: 12-country reliability and validity. Med Sci Sports Exerc 35:1381-1395

Duijts SFA, Kant IJ, Swaen GMH, Van den Brandt PA, Zeegers MPA (2007) A meta-analysis of observational studies identifies predictors of sickness absence. J Clin Epidemiol 60:11051115. doi:10.1016/j.jclinepi.2007.04.008 
Elders LA, Burdorf A (2001) Interrelations of risk factors and low back pain in scaffolders. Occup Environ Med 58:597-603. doi: 10.1136/oem.58.9.597

Gates DM, Succop P, Brehm BJ, Gillespie GL, Sommers BD (2008) Obesity and presenteeism: the impact of body mass index on workplace productivity. J Occup Environ Med 50:39-45. doi: 10.1097/JOM.0b013e31815d8db2

Hansen AM, Blangsted AK, Hansen EA, Sogaard K, Sjogaard G (2010) Physical activity, job demand control, perceived stressenergy, and salivary cortisol in white-collar workers. Int Arch Occup Environ Health 83:143-153. doi:10.1007/s00420-0090440-7

Kamphuis CB, Van Lenthe FJ, Giskes K, Huisman M, Brug J, Mackenbach JP (2008) Socioeconomic status, environmental and individual factors, and sports participation. Med Sci Sports Exerc 40:71-81. doi:10.1249/mss.0b013e318158e467

Koopmanschap M, Burdorf A, Jacob K, Meerding WJ, Brouwer W, Sverens H (2005) Measuring productivity changes in economic evaluation: setting the agenda. Pharmacoeconomics 23:47-54

Kunst AE, Bos V, Lahelma E, Bartley M, Lissau I, Regidor E et al (2005) Trends in socioeconomic inequalities in self-assessed health in 10 European countries. Int J Epidemiol 34:295-305. doi:10.1093/ije/dyh342

Laaksonen M, Piha K, Martikainen P, Rahkonen O, Lahelma E (2009) Health-related behaviours and sickness absence from work. Occup Environ Med 66:840-847. doi:10.1136/oem.2008.039248

Laaksonen M, Piha K, Rahkonen O, Martikainen P, Lahelma E (2010a) Explaining occupational class differences in sickness absence: results from middle-aged municipal employees. J Epidemiol Community Health 64:802-807. doi:10.1136/jech.2009. 093385

Laaksonen M, Pitkaniemi J, Rahkonen O, Lahelma E (2010b) Work arrangements, physical working conditions, and psychosocial working conditions as risk factors for sickness absence: Bayesian analysis of prospective data. Ann Epidemiol 20:332-338. doi: 10.1016/j.annepidem.2010.02.004

Leinonen T, Pietiläinen O, Laaksonen M, Rahkonen O, Lahelma E, Martikainen P (2011) Occupational social class and disability retirement among municipal employees - the contribution of health behaviours and work conditions. Scand J Work Environ Health 37:464-472

Lund T, Labriola M, Christensen KB, Bultmann U, Villadsen E (2006) Physical work environment risk factors for long term sickness absence: prospective findings among a cohort of 5357 employees in Denmark. BMJ 332:449-452. doi:10.1136/bmj. 38731.622975.3A

Mackenbach JP, Stirbu I, Roskam AJ, Schaap MM, Menvielle G, Leinsalu $\mathrm{M}$ et al (2008) Socioeconomic inequalities in health in 22 European countries. N Engl J Med 358:2468-2481

Martimo KP, Shiri R, Miranda H, Ketola R, Varonen H, ViikariJuntura E (2009) Self-reported productivity loss among workers with upper extremity disorders. Scand J Work Environ Health 35:301-308

Meerding WJ, IJzelenberg W, Koopmanschap MA, Severens JL, Burdorf A (2005) Health problems lead to considerable productivity loss at work among workers with high physical load jobs. J Clin Epidemiol 58:517-523. doi:10.1016/j.jclinepi.2004.06. 016

Melchior M, Krieger N, Kawachi I, Berkman LF, Niedhammer I, Goldberg M (2005) Work factors and occupational class disparities in sickness absence: findings from the GAZEL cohort study. Am J Public Health 95:1206-1212. doi:10.2105/AJPH. 2004.048835

Moreau M, Valente F, Mak R, Pelfrene E, De Smet P, De Backer G et al (2004) Occupational stress and incidence of sick leave in the Belgian workforce: the Belstress study. J Epidemiol Community Health 58:507-516. doi:10.1136/jech.2003.007518

Neovius K, Johansson K, Kark M, Neovius M (2009) Obesity status and sick leave: a systematic review. Obes Rev 10:17-27. doi: 10.1111/j.1467-789X.2008.00521.x

Niedhammer I, Chastang JF, David S, Kelleher C (2008) The contribution of occupational factors to social inequalities in health: findings from the national French SUMER survey. Soc Sci Med 67:1870-1881. doi:10.1016/j.socscimed.2008.09.007

Pronk NP, Martinson B, Kessler RC, Beck AL, Simon E, Wang P (2004) The association between work performance and physical activity, cardiorespiratory fitness, and obesity. J Occup Environ Med 46:19-25. doi:10.1097/01.jom.0000105910.69449.b7

Rael EG, Stansfeld SA, Shipley M, Head J, Feeney A, Marmot M (1995) Sickness absence in the Whitehall II study, London: the role of social support and material problems. J Epidemiol Community Health 49:474-481

Robroek SJW, Van Lenthe FJ, Van Empelen P, Burdorf A (2009) Determinants of participation in worksite health promotion programmes: a systematic review. Int $\mathrm{J}$ Behav Nutr Phys Act 6:26. doi:10.1186/1479-5868-6-26

Robroek SJW, Van den Berg TIJ, Plat JF, Burdorf A (2011) The role of obesity and lifestyle behaviours in a productive workforce. Occup Environ Med 68:134-139. doi:10.1136/oem.2010.055962

Schrijvers CT, Van de Mheen HD, Stronks K, Mackenbach JP (1998) Socioeconomic inequalities in health in the working population: the contribution of working conditions. Int J Epidemiol 27:10111018. doi:10.1093/ije/27.6.1011

Schultz AB, Edington DW (2007) Employee health and presenteeism: a systematic review. J Occup Rehabil 17:547-579. doi:10.1007/ s10926-007-9096-x

Schuring M, Burdorf A, Kunst A, Voorham T, Mackenbach J (2009) Ethnic differences in unemployment and ill health. Int Arch Occup Environ Health 82:1023-1030. doi:10.1007/s00420-0090408-7

Smith PM, Frank JW, Mustard CA, Bondy SJ (2008) Examining the relationships between job control and health status: a path analysis approach. J Epidemiol Community Health 62:54-61. doi:10.1136/jech.2006.057539

Statistics Netherlands (2004). Foreigners in the Netherlands (Allochtonen in Nederland). Statistics Netherlands, Voorburg. (Published in Dutch)

Tuomi K, Ilmarinen J, Jakhola A, Katajarinne L, Tulkki A (1998) Work ability index. Finnish Institute of Occupational Health, Helsinki

Twisk JWR (2003) Applied longitudinal data analyses for epidemiology. A practical guide. Cambridge University Press, Cambridge, UK

Van Duijvenbode DC, Hoozemans MJ, Van Poppel MN, Proper KI (2009) The relationship between overweight and obesity, and sick leave: a systematic review. Int J Obes 33:807-816. doi: 10.1038/ijo.2009.121

Van Veldhoven M, Meijman T (1994). Het meten van psychosociale arbeidsbelasting met een vragenlijst: de Vragenlijst Beleving en Beoordeling van de Arbeid (VBBA) (Dutch Questionnaire on psychosocial job demands and job stress). NIA, Amsterdam. (Published in Dutch)

Ware J Jr, Kosinski M, Keller SD (1996) A 12-Item Short-Form Health Survey: construction of scales and preliminary tests of reliability and validity. Med Care 34:220-233

Zajacova A, Dowd JB (2011) Reliability of self-rated health in US adults. Am J Epidemiol 174:977-983. doi:10.1093/aje/kwr204

Zhang W, Bansback N, Anis AH (2011) Measuring and valuing productivity loss due to poor health: a critical review. Soc Sci Med 72:185-192. doi:10.1016/j.socscimed.2010.10.026 